\title{
Laparoscopic ureteropyeloanastomosis in the treatment of duplex system
}

\author{
Marcelo Hisano, Francisco T. Denes, Artur H. Brito, Marcos Lucon, Marcos G. Machado, Homero \\ Bruschini, Miguel Srougi
}

Urologic Clinic, Hospital das Clinicas, University of Sao Paulo, Brazil

\section{ABSTRACT}

Purpose: Duplex system is one of the most common anomalies of upper urinary tract. Anatomical and clinical presentation determine its treatment. Usually, the upper moiety has a poor function and requires resection, but when it is not significantly impaired, preservation is recommended. Laparoscopic reconstruction with upper pole preservation is presented as an alternative treatment.

Materials and Methods: Four female patients with duplex system, one presenting with recurrent urinary tract infection and the others with urinary incontinence associated to infrasphincteric ectopic ureter, were treated. Surgical procedure envolved a laparoscopic ureteropyeloanastomosis of the upper pole ureter to the pelvis of the lower moiety, with prior insertion of a double J stent.

Results: Surgical time varied from 120 to 150 minutes, with minimal blood loss in all cases. Follow-up varied from 15 to 30 months, with resolution of the clinical symptoms and preservation of the upper moiety function.

Conclusion: Laparoscopic ureteropyeloanatomosis is a feasible and safe minimally invasive option in the treatment of duplex system.

\section{ARTICLE INFO}

\section{Key words:}

laparoscopy; kidney; congenital abnormalities

Int Braz J Urol. 2012; 38: 235-41

Submitted for publication:

February 11, 2011

Accepted after revision:

August 12, 2011

\section{INTRODUCTION}

Pyeloureteral duplication or duplex system is one of the most common anomalies of the upper urinary tract (1). Embryologically, a complete duplex system arises from two separate ureteric buds and is more common in girls than boys, in a ratio of $6: 1$. It has a broad spectrum of clinical presentations and significance. Girls may present with urinary incontinence associated to normal voiding after toilet training, due to the ectopic orifice of the ureter of the upper unit, which opens in the urethra distally to the external sphincter, or in the introitus. This ureter may also end in an intravesical ureterocele that obstructs this unit and, depending on its size and location, all other units and the bladder neck. The ureter of the lower pole generally ends in the bladder but has a short intravesical tunnel, often leading to vesico-ureteral reflux (VUR). While the lower unit is usually preserved anatomically and functionally, that of the upper moiety is frequently dilated or dysplastic (2).

Many treatment alternatives are available, depending on the functional and anatomical status of the affected units, as well as the size, location and degree of obstruction of the ureterocele or ectopic ureter, and the presence of urinary incontinence. If renal function in one moiety is very poor, as frequently observed in the upper 
unit, polar nephrectomy is the most appropriate procedure. However, when the anatomical and functional impairment of this moiety is not significant, it may be preserved, therefore requiring a reconstruction either by a proximal ureteropyeloanastomosis, a distal uretero-uretero anastomosis or a vesicoureteral reimplantation (3-5).

In the last decade, laparoscopy has become a safe and effective modality for the treatment of pediatric urologic anomalies that require ablative or reconstructive techniques (6-8). Laparoscopic polar nephrectomy is now considered the standard of care of duplex systems, when the upper moiety is to be removed $(9,10)$. Laparoscopic intervention in duplex systems to preserve the upper unit is naturally more demanding, but with the technical improvements and growing experience with laparoscopic pyeloplasty, more centers are able to perform this procedure $(9,11,12)$.

We report our experience with the laparoscopic treatment of duplex systems associated to ectopic ureters and preservation of the affected renal unit.

\section{MATERIALS AND METHODS}

In this retrospective series, we report four female patients with duplex kidneys who underwent laparoscopic ureteropyeloanastomosis. An informed consent was obtained from all patients or parents.

None of our patients had antenatal diagnosis, and were referred to our department at late age, without diagnosis of duplex kidney. Medium time of diagnosis was 12 years of age, varying from 8 to 19 years. No patient had previous surgical treatment. Two younger patients presented continuous urinary leakage associated to normal voiding, another young patient presented with recurrent urinary tract infections, while the older patient had intermittent urinary leakage associated to normal voiding; the patient with recurrent urinary tract infections was on antibiotic prophylaxis with trimethoprim from the first consultation until stent removal after the surgery. Blood pressure and serum creatinine were measured in all patients before and after surgery, during follow-up consultations.
The diagnosis of duplex system was suspected by clinical data and ultrasound examination, and confirmed in all cases by computerized tomography (CT) or intravenous pyelogram (IVP). Preservation of the upper moeity was based subjectively on the degree of its pyelocalicial dilatation, the thickness of its parenchyma and degree of its function, as evaluated by contrast excretion, either by DMSA exam or IVP (other patients, with significant anatomical or functional impairment of the upper moieties, were submitted to polar nephrectomy). A micturating cystography was also performed in all patients, to exclude vesico-ureteric reflux.

A three or four ports laparoscopic transperitoneal approach was performed in all patients, with previous double-J stenting of the ureter of the lower unit and insertion of a Foley catheter into the bladder. After colonic mobilization, the kidney was exposed and both ureters were isolated at the lower pole of the kidney. The ureter of the lower moiety was easily identified by the presence of the inserted double-J stent. The ureter of the upper moiety, usually dilated, was separated and carefully dissected as far down as possible, care being taken to preserve the integrity of the ureter of the lower unit. The ureter of the upper moiety was then sectioned at it lowermost segment and its lower stump left open in the absence of VUR. The upper stump was dissected upwards, until very close to the vascular pedicle of the kidney, where the pelvis of the lower unit was also exposed. A stay suture could have been inserted through the abdominal wall, in order to stabilize the lower pole and facilitate dissection of the hilar structures. The ureter of the upper moiety was again sectioned and spatulated close to the pelvis of the lower unit, while the later was incised longitudinally. An end-to-side free-hand anastomosis between both structures was then performed with running 4.0 or 5.0 Vicryl suture (Figure-1). In three cases, the double-J stent was maintained in the pelvis of the lower unit, while in one it was transposed to the ureter of the upper unit. When the anastomosis was completed, the stay suture was transected and a Penrose or suction drain inserted through one of the accesses, being removed the next day. The Foley catheter 


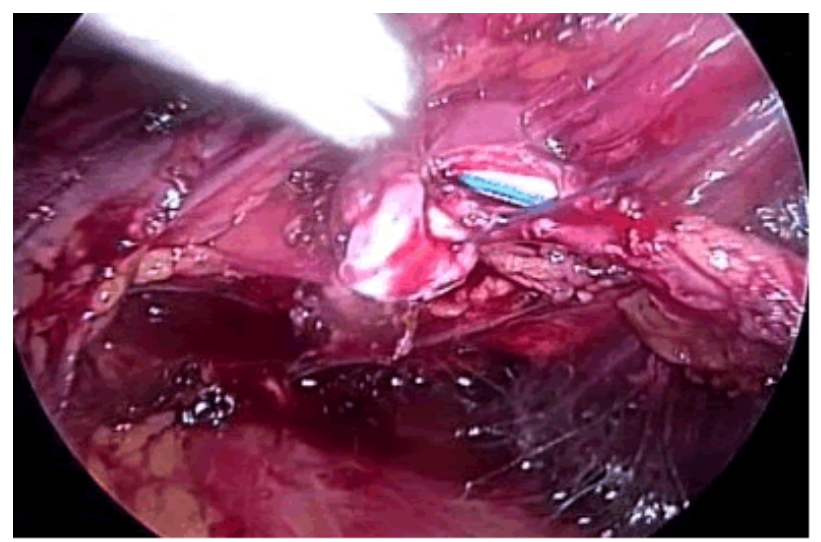

Figure 1 - Intraoperative view of end-to-side ureteropyeloanastomosis (case 4).

was usually removed in the second post-operative day, prior to discharge of the patient. The double$\mathrm{J}$ catheter was removed after 4-5 weeks. Control urinalysis was made after completion of antibiotic prophylaxis.

Patients were operated on by two of the authors (M.H. and F.T.D.), both experienced in reconstructive laparoscopy.

Post-operative evaluation was based on clinical data (cessation of urinary leakage), as well as routine US control, in order to evaluated dilatation of both moieties, followed by DMSA, IVP or CT evaluation to functionally evaluate the upper moiety every six months.

\section{RESULTS}

Clinical data of patients are summarized in Table-1. All had evidence of unilateral pyeloureteral duplication with a dilated, but functioning upper moiety, and a normal lower moiety. None had preoperative VUR to any of the units. All cases were operated laparoscopically and the operative time (OT) varied from 120 to $150 \mathrm{~min}$ utes. Blood loss was minimal in all cases, and there was no post-operative morbidity. All patients were discharged after the removal of the bladder catheter. The first patient had no more UTIs, nor flank pain, while the other patients had immediate cure of the urinary incontinence.

Follow-up varied from 15 to 60 months, with a medium time of 40.2 months, and post-operative IVP or CT showed functioning upper and lower poles with good drainage of both moieties in all patients (Figures 2-5). Patient number 4 had a one year post-operative renal scan with a renal function of 51\% on the operated kidney and no obstruction after furosemide. Blood pressure and serum creatinine did not change after surgery.

\section{DISCUSSION}

Ureteropyeloanastomosis is an alternative treatment of duplex system, when the up-

Table 1 - Clinical data of patients.

\begin{tabular}{|c|c|c|c|c|c|c|c|}
\hline Case & Sex & Age & Side & Symptoms & Past Hystory & Physical Exam & Diagnosis \\
\hline 1 & q & 8 years & $\mathrm{R}$ & $\begin{array}{l}\text { Recurrent UTI } \\
\text { Flank pain }\end{array}$ & - & Normal & $\begin{array}{c}\text { Suprasphincteric ectopic } \\
\text { ureterocele }\end{array}$ \\
\hline 2 & $q$ & 8 years & $\mathrm{L}$ & Incontinence & - & $\begin{array}{c}\text { Continuous } \\
\text { urinary vaginal } \\
\text { leakage }\end{array}$ & $\begin{array}{c}\text { Infrasphincteric ectopic } \\
\text { ureter }\end{array}$ \\
\hline 3 & o & 19 years & $\mathrm{L}$ & Incontinence & $\begin{array}{c}\text { Pregnancy } \\
\text { and vaginal } \\
\text { delivery }\end{array}$ & $\begin{array}{c}\text { Continuous } \\
\text { urinary vaginal } \\
\text { leakage }\end{array}$ & $\begin{array}{c}\text { Infrasphincteric ectopic } \\
\text { ureter }\end{array}$ \\
\hline 4 & 우 & 14 years & $\mathrm{L}$ & Incontinence & - & $\begin{array}{c}\text { Continuous } \\
\text { urinary vaginal } \\
\text { leakage }\end{array}$ & $\begin{array}{c}\text { Infrasphincteric ectopic } \\
\text { ureter }\end{array}$ \\
\hline
\end{tabular}




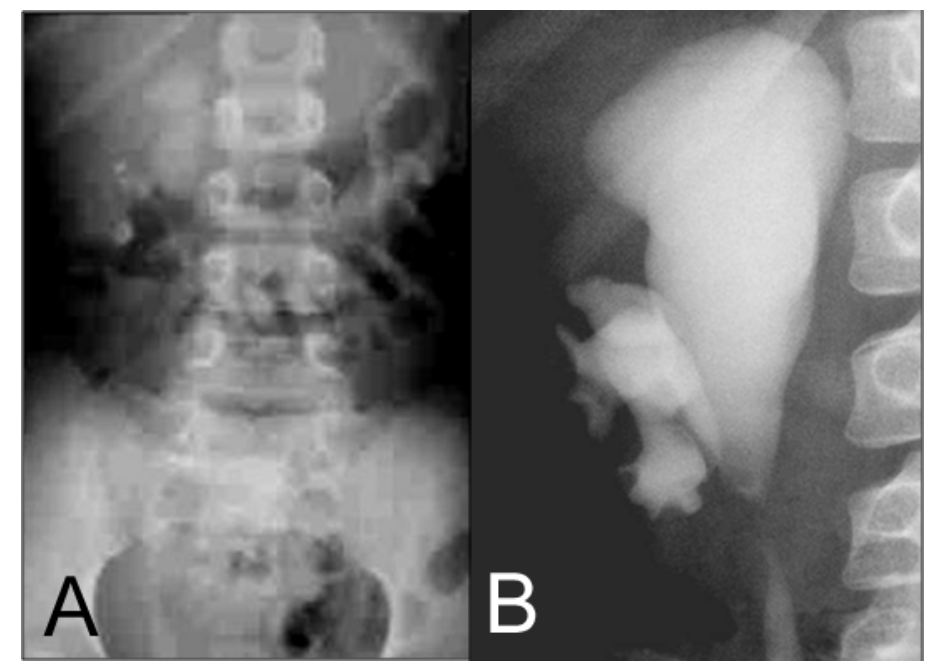

Figure 2 -A) Pre-operative IVP in case 1; B) Post-operative IVP 6 months after procedure

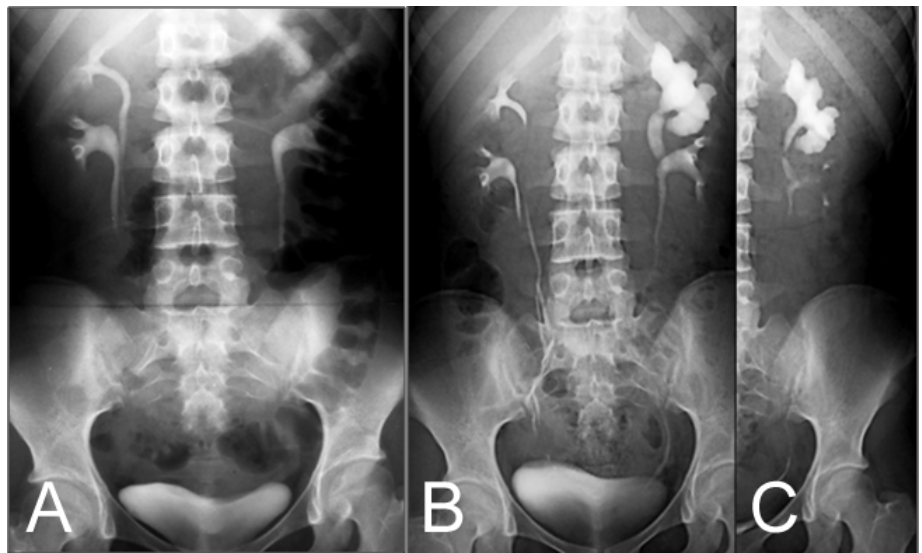

Figure 3 - A) Pre-operative IVP in case 2; B and C) Post-operative IVP 4 months after procedure.

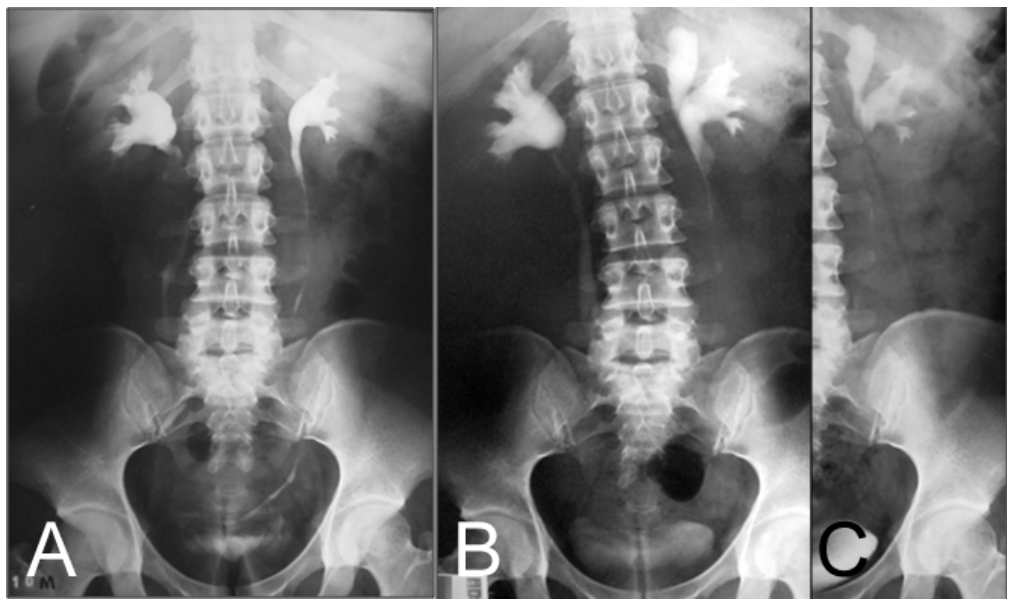

Figure 4 - A) Pre-operative IVP in case 3; B and C) Post-operative IVP 6 months after procedure. 


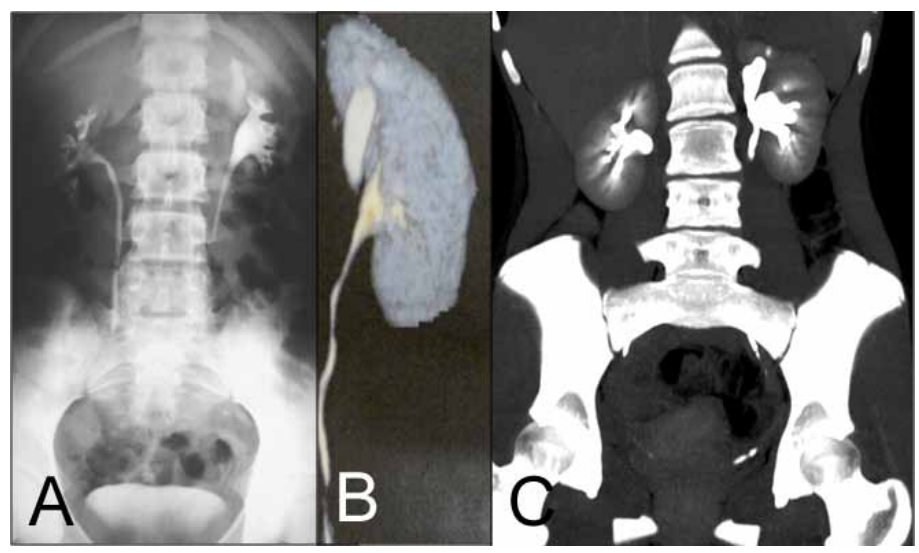

Figure 5 - A) Pre-operative IVP in case 4; B) Pre-operative CT reconstruction; and C) Post-operative CT 6 months after procedure.

per moiety is to be preserved. According to DiazBall et al. (5) ureteropyeloanastomosis for duplex system was first performed by Kummel in 1913, for the treatment of ectopic ureterocele. Laparoscopic procedures for duplex system treatment were introduced by Suzuki et al. in 1993 (13). Until now, there are some case series with laparoscopic reconstruction for duplex system, but clinical presentation is generally different, usually due to urinary infection, upper tract obstruction or reflux. There are few reports on laparoscopic treatment for urinary incontinence due to ectopic ureter in duplex system $(14,15)$. Ramalingam et al. (11) described three cases of laparoscopic ureteropyeloanastomosis, two for duplex system associated to ureteropyelo-junction (UPJ) obstruction and one for duplex system associated to reflux. Kutikov et al. (12) was the first to describe laparoscopic ureteropyeloanastomosis in the treatment of duplex system in 6 children: four girls with ureteral ectopy and incontinence, one with bilateral ectopy and a boy with ureteral ectopy to the prostate.

Treatment of incontinence due to ectopic ureter with functioning upper pole can be performed at the level of the kidney (ureteropyeloanastomosis), lower ureter (uretero-ureteroanastomosis) or bladder (ureteral reimplantation). The first two procedures can be performed only when there is no VUR to any of the ureters, while the latter is the ideal procedure when VUR is present. Ureteropyeloanastomosis allows the removal of the distal dilated segment of the ureter of the upper unit and also precludes the "yo-yo" reflux (urinary reflux from the healthy ureter to the massively dilated lower ureteral segment of the upper unit), which can lead to urinary stasis and infection when uretero-ureteroanastomosis is performed (3). Khoubehi et al. (16) described a laparoscopic ureteropyelostomy for symptomatic "yo-yo" reflux in an adult with partial duplication. Furthermore, ureteropyelostomy is devoid of the risk of postoperative VUR or obstruction that can occurs after reimplantation of duplex ureters. It is important to emphasize that VUR to the lower pole recipient ureter must be excluded; therefore a cystography is mandatory preoperatively. A renal DMSA scintigraphy can be performed if there is doubt on the upper pole function (1-3). In our series, the preoperative imagenological evaluation ensured us on the residual upper pole function, which was then preserved with the procedure.

Ureteropyeloanastomosis can be technically demanding, mainly when pelvic and ureteral dilation is small or absent. There is also a potential risk of bleeding when working close to renal vessels as well as an impairment of the healthy lower pole if an anastomotic stricture occurs (3). Double-J catheter can be inserted before, 
during or after the anastomosis. In our series, retrograde stenting of the lower pole ureter was performed at the beginning of the procedure, facilitating its identification and dissection during the procedure. Also, it facilitates the longitudinal incision of the pelvis of the lower moeity, without damaging the opposite wall $(17,18)$. After completion of the posterior lip of the anastomosis, transposition of the stent to the ureter of the upper unit, as performed in one of our cases, did not influence the end-result. The decision to transpose the stent was aleatory, not based on the intraoperative appearance of the anastomosis or the local condition of the recipient renal pelvis. The distal ureteral segment of the upper pole can be excised as distally as possible, but care must be taken to avoid damage to the lower pole ureter. Its stump may be left open as it is ectopic and as long as there is no urinary drainage due to VUR $(4,12)$. In all of our cases it was left open, with no adverse consequences.

Since our patients did not have antenatal diagnosis, their medium age of treatment was 12 years, in contrast to that described in the literature (from six months to five years) $(1,3,12,19)$. One of them had even been pregnant and had a normal delivery before duplex system with infrasphincteric ectopic ureter was diagnosed. All of them had sought medical care before being referred to our service, but were treated clinically due to lack of correct diagnosis. The laparoscopic ureteropyeloanastomosis, with preservation of the upper moiety, was successful in all our patients, despite their age, and we recommend it in the treatment of younger children, who are regularly submitted to other laparoscopic procedures $(6,20)$.

\section{CONCLUSIONS}

Laparoscopic ureteropyeloanastomosis is a feasible treatment for duplex kidneys associated to a functioning upper moiety. In our series, we had a success rate of 100\%, without morbidity or mortality. It can be considered as an option of minimally invasive treatment in cases with upper pole preservation.

\section{ABBREVIATIONS}

UTI: urinary tract infection

VUR: vesico-ureteral reflux

CT: computerized tomography

IVP: intravenous pyeloghram

OT: operative time

\section{CONFLICT OF INTEREST}

None declared.

\section{REFERENCES}

1. Siomou E, Papadopoulou F, Kollios KD, Photopoulos A, Evagelidou E, Androulakakis $P$ et al.: Duplex collecting system diagnosed during the first 6 years of life after a first urinary tract infection: a study of 63 children. J Urol. 2006; 175: 678-81; discussion 681-2.

2. Decter RM: Renal duplication and fusion anomalies. Pediatr Clin North Am. 1997; 44: 1323-41.

3. Choi H, Oh SJ: The management of children with complete ureteric duplication: selective use of uretero-ureterostomy as a primary and salvage procedure. BJU Int. 2000; 86 : 508-12.

4. Huisman TK, Kaplan GW, Brock WA, Packer MG: Ipsilateral ureteroureterostomy and pyeloureterostomy: a review of 15 years of experience with 25 patients. J Urol. 1987; 138: 1207-10.

5. Diaz-Ball FL, Fink A, Moore CA, Gangai MP: Pyeloureterostomy and ureteroureterostomy: alternative procedures to partial nephrectomy for duplication of the ureter with only one pathological segment. J Urol. 1969; 102: 621-6.

6. Vicentini FC, Dénes FT, Borges LL, Silva FA, Machado MG, Srougi M: Laparoscopic pyeloplasty in children: Is the outcome different in children under 2 years of age? J Pediatr Urol. 2008; 4: 348-51.

7. Peters CA, Schlussel RN, Retik AB: Pediatric laparoscopic dismembered pyeloplasty. J Urol. 1995; 153: 1962-5.

8. Peters CA: Laparoendoscopic renal surgery in children. J Endourol. 2000; 14: 841-7; discussion 847-8

9. Janetschek G, Seibold J, Radmayr C, Bartsch G: Laparoscopic heminephroureterectomy in pediatric patients. J Urol. 1997; 158: 1928-30.

10. Denes FT, Danilovic A, Srougi M: Outcome of laparoscopic upper-pole nephrectomy in children with duplex systems. J Endourol. 2007; 21: 162-8.

11. Ramalingam M, Selvarajan K, Senthil K, Pai MG: Laparoscopic pyeloureterostomy: experience in three cases. J Endourol. 2006; 20: 115-8. 
12. Kutikov A, Nguyen M, Guzzo T, Canter D, Casale P: Laparoscopic and robotic complex upper-tract reconstruction in children with a duplex collecting system. J Endourol. 2007; 21: $621-4$.

13. Suzuki K, Ihara H, Kurita $\mathrm{Y}$, Kageyama S, Ueda D, Ushiyama T et al.: Laparoscopic nephrectomy for atrophic kidney associated with ectopic ureter in a child. Eur Urol. 1993; 23: 463-5

14. Liu KK, Yeung CK, Lee KH, Ku KW: Ectopic ureter as a cause of wetting: the role of laparoscopy in its management. Aust N Z J Surg. 1996; 66: 325-6.

15. Jordan GH, Winslow BH: Laparoendoscopic upper pole partial nephrectomy with ureterectomy. J Urol. 1993; 150: 940-3.

16. Khoubehi B, Woodhouse CR, Rowe E, Boustead G, Hrouda D: Report of laparoscopic ureteropyelostomy for symptomatic "yo-yo" reflux in an adult. Urology. 2006; 68: 203. e7-9.

17. Lowe GJ, Canon SJ, Jayanthi VR: Laparoscopic reconstructive options for obstruction in children with duplex renal anomalies. BJU Int. 2008; 101: 227-30.

\section{EDITORIAL COMMENT}

A duplex renal system is one of the most common urological anomalies that would be seen in practice. Clinical presentation can be highly varied and management must be tailored case by case. Traditionally, a poorly functioning upper pole moiety was dealt by performing a partial nephrectomy in an open fashion. Nowadays, many centers utilize laparoscopic partial nephrectomy as the treatment of choice for managing such cases. However, a chal-
18. González R, Piaggio L: Initial experience with laparoscopic ipsilateral ureteroureterostomy in infants and children for duplication anomalies of the urinary tract. J Urol. 2007; 177: 2315-8.

19. Plaire JC, Pope JC 4th, Kropp BP, Adams MC, Keating MA, Rink RC et al.: Management of ectopic ureters: experience with the upper tract approach. J Urol. 1997; 158: 1245-7.

20. Ansari MS, Mandhani A, Singh P, Srivastava A, Kumar A, Kapoor R: Laparoscopic pyeloplasty in children: long-term outcome. Int J Urol. 2008; 15: 881-4.

pyeloplasty in children: Is the outcome different in children under 2 years of age? J Pediatr Urol. 2008; 4: 348-51.

Correspondence address:

Dr. Francisco T. Dénes

Hospital das Clínicas, University of São Paulo

Av. Dr. Enéas de Carvalho Aguiar, 255 -

Cerqueira César, 05403-000, SP, Brazil

Telephone: +55 11 3069-8080

E-mail: ftdenes@gmail.com

lenging scenario is one where the upper pole moiety has clinical significant function and preservation is desired. Dr. Hisano and colleagues describe their approach of a laparoscopic ureteropyelotomy and present data supporting their clinical success. Their group has delineated step by step how laparoscopic ureteropyelotomy is feasible and an excellent option for preserving the upper pole moiety and addressing the ectopic ureter. The laparoscopic ureteropyeloanastomosis is a technique that one should consider for this often seen problem.

Dr. Edward D. Matsumoto Associate Professor Division of Urology McMaster University St. Joseph's Hospital 50 Charlton Ave. E. G343 Hamilton, ON L8N 4A6, Canada Fax: + 905 308-7205

E-mailmatsumo@mcmaster.ca 